\title{
Proteolysis of Ambra1 during apoptosis has a role in the inhibition of the autophagic pro-survival response
}

\author{
V Pagliarini ${ }^{1}$, E Wirawan ${ }^{2,3}$, A Romagnoli ${ }^{1}$, F Ciccosanti ${ }^{1}$, G Lisi ${ }^{1}$, S Lippens ${ }^{2,3}$, F Cecconi ${ }^{4,5}$, GM Fimia ${ }^{1}$, P Vandenabeele ${ }^{2,3}$, \\ M Corazzari; ${ }^{, 1,7}$ and M Piacentini ${ }^{*, 1,6,7}$
}

Under stress conditions, pro-survival and pro-death processes are concomitantly activated and the final outcome depends on the complex crosstalk between these pathways. In most cases, autophagy functions as an early-induced cytoprotective response, favoring stress adaptation by removing damaged subcellular constituents. Moreover, several lines of evidence suggest that autophagy inactivation by the apoptotic machinery is a crucial event for cell death execution. Here we show that apoptotic stimuli induce a rapid decrease in the level of the autophagic factor Activating Molecule in Beclin1-Regulated Autophagy (Ambra1). Ambra1 degradation is prevented by concomitant inhibition of caspases and calpains. By both in vitro and in vivo approaches, we demonstrate that caspases are responsible for Ambra1 cleavage at the D482 site, whereas calpains are involved in complete Ambra1 degradation. Finally, we show that Ambra1 levels are critical for the rate of apoptosis induction. RNA interference-mediated Ambra1 downregulation further sensitizes cells to apoptotic stimuli, while Ambra1 overexpression and, more efficiently, a caspase non-cleavable mutant counteract cell death by prolonging autophagy induction. We conclude that Ambra1 is an important target of apoptotic proteases resulting in the dismantling of the autophagic machinery and the accomplishment of the cell death program.

Cell Death and Differentiation (2012) 19, 1495-1504; doi:10.1038/cdd.2012.27; published online 23 March 2012

Stress stimuli activate multiple parallel pathways, responsible for either tolerating adverse conditions or triggering cell-suicide mechanisms. One of the early adaptive cellular responses, activated in many stress conditions, is autophagy. Autophagy is a catabolic process that occurs at low, constitutive levels in favorable conditions and is upregulated under physiological stress, such as nutrient deprivation, growth-factor withdrawal and hypoxia. ${ }^{1}$ The process involves the sequestration of cytoplasmic material by double-membrane vesicles, called autophagosomes, which deliver their contents to lysosomes for degradation. ${ }^{2}$ This 'self-eating' process not only clears the cell of misfolded proteins, damaged organelles or invading microorganisms; ${ }^{3}$ it also generates metabolic substrates to meet the bioenergetic needs of cells and to allow adaptive protein synthesis. ${ }^{1}$ In most cases, autophagy functions as a cytoprotective mechanism, favoring stress adaptation that avoids cell death. However, several reports also suggest that autophagy contributes to cell death execution when apoptotic signaling is compromised. ${ }^{4,5}$ Although a physiological role of autophagy in cell death remains a matter for debate, there is evidence that autophagy may favour cell death by the selective removal of survival factors or by prolonged removal of cellular constituents, this resulting in the efficient demise of the cell. $^{6-9}$

Besides the pro-survival and pro-death roles of autophagy, what it is now well established is the existence of a complex regulatory interplay between autophagy and apoptosis. There is evidence to indicate that these processes share common regulatory factors. ${ }^{10}$ For example, $\mathrm{Bcl}-2$ and $\mathrm{Bcl}-\mathrm{X}_{\mathrm{L}}$, two wellcharacterized anti-apoptotic proteins, are able to bind Beclin1, a core protein of the autophagy-inducing complex, and inhibit autophagy. ${ }^{11-13}$ It has been further suggested that the tumor suppressor and apoptosis inducer p53 has a positive role in cell survival in response to stress, stimulating antioxidant pathways and, more importantly, autophagy. ${ }^{11}$ The crosstalk between autophagy and apoptosis is further highlighted by data showing mutual regulation of these pathways through modification of each others' activity. On the one hand, it has been demonstrated that inhibiting the cleavage of several

\footnotetext{
${ }^{1}$ National Institute for Infectious Diseases I.R.C.C.S. 'L. Spallanzani', Rome, Italy; ${ }^{2}$ VIB, Department for Molecular Biomedical Research, Molecular Signalling and Cell Death Unit, Technologiepark 927, B-9052 Ghent, Belgium; ${ }^{3}$ Ghent University, Department of Biomedical Molecular Biology, Molecular Signalling and Cell Death Unit, Technologiepark 927, B-9052 Ghent, Belgium; ' ${ }^{4}$ Dulbecco Telethon Institute at the Department of Biology, University of Rome 'Tor Vergata', 00133 Rome, Italy; ${ }^{5}$ Laboratory of Molecular Neuroembryology, IRCCS Fondazione Santa Lucia, 00143 Rome, Italy and 'Department of Biology, University of Rome 'Tor Vergata', Rome, Italy

*Corresponding author: M Piacentini, Department of Biology, University of Rome 'Tor Vergata', Via della Ricerva Scientifica 1, 00173 Rome, Italy. Tel: + 39067259 4234; Fax: + 39067259 4222; E-mail: mauro.piacentini@uniroma2.it

or M Corazzari, National Institute for Infectious Diseases I.R.C.C.S. 'L. Spallanzani', Via Portuense 292, 00149 Rome, Italy. Tel: + 390655170916 ;

Fax: + 39065582 825; E-mail: marco.corazzari@ inmi.it

${ }^{7}$ These authors are joint senior authors.

Keywords: apoptosis; autophagy; Ambra1; caspases; calpains

Abbreviations: Ambra1, activating molecule in beclin1-regulated autophagy; CHX, cycloheximide; STS, staurosporine; siRNA, small interfering RNA; TNF $\alpha$, tumor necrosis factor; MTT, [3-(4,5-Dimethylthiazol-2-yl)-2,5-diphenyltetrazolium bromide; PI, propidium iodide; TRAIL, TNF-related apoptosis-inducing ligand; PI3KC3, phosphatidylinositol 3-kinase class 3

Received 26.5.11; revised 13.2.12; accepted 13.2.12; Edited by G Melino; published online 23.3.12
} 
crucial autophagy-related proteins by apoptotic executioner proteases favors the autophagy pro-survival functions and counteracts cell death. ${ }^{14-17}$ However, Hou et al. ${ }^{18}$ recently demonstrated the autophagic degradation of a subunit of the active caspase-8 enzyme during TNF-related apoptosisinducing ligand-induced autophagy, keeping the apoptotic response at bay. These results support the existence of crossregulatory mechanisms between both cell fate-determining processes, so that only one process can prevail.

Ambra1 (Activating Molecule in Beclin1-Regulated Autophagy) is an important regulator of the autophagic process. ${ }^{19-21}$ Ambra1 promotes Beclin1 interaction with its target lipid kinase Vps34/PI3KC3 (phosphatidylinositol-3-OH kinase) to assemble a class III PI3KC3 complex, thus mediating the initial steps of autophagosome formation. ${ }^{19}$ Proautophagic activity of Ambra1 is negatively regulated by the interaction to the dynein complex on cytoskeleton and by direct association with $\mathrm{Bcl}-2$ on the mitochondrial outer membrane. ${ }^{20,21}$ Functional deficiency of Ambra1 in mice causes defects in the developing nervous system and embryonic death both associated with autophagy impairment, increased proliferation and a large number of supernumerary apoptotic cells. ${ }^{19,22}$ In particular, the latter aspect of this multifaceted phenotype prompted us to investigate the role of Ambra1 during apoptosis. We found that Ambra1 degradation is an early event during apoptosis and occurs in a caspase- and calpain-dependent manner. Ambra1 cleavage contributes to the onset of apoptosis, as the expression of a non-cleavable Ambra1 mutant partially prevents apoptosis execution by prolonging the pro-survival function of autophagy.

\section{Results}

Ambra1 is degraded during apoptosis execution. Cleavage of specific pro-autophagic factors by apoptotic proteases has been proposed as one of the mechanisms responsible for the inhibition of pro-survival autophagy. ${ }^{14-17}$ In light of these findings, and as an increased number of apoptotic cells could be observed in Ambra1-deficient mice, ${ }^{19}$ we decided to study the involvement of the autophagic protein Ambra1 in apoptosis execution.

First, we analyzed Ambra1 levels following apoptosis induction. Human fibroblast $2 \mathrm{FTGH}(2 \mathrm{~F})$ cells were treated with staurosporine for 2, 4, 6 and $8 \mathrm{~h}$, and Ambra1 expression levels were evaluated by western blot analysis. A significant decrease in the endogenous protein level of Ambra1 was observed starting from $4 \mathrm{~h}$ of staurosporine treatment (Figure 1a). Interestingly, Ambra1 reduction occurred concomitantly with caspase activation as monitored by poly (ADP-ribose)polymerase (PARP) cleavage (Figure 1a). We also performed a dose-response Ambra1 expression analysis by treating $2 \mathrm{~F}$ cells for $8 \mathrm{~h}$ with decreasing concentrations of staurosporine. Results reported in Figure 1b show a dosedependent decrease of Ambra1 protein correlating with the rate of caspase activation, as indicated by PARP cleavage (Figure 1b), and the levels of cell death analyzed both by DNA fragmentation (data not shown) and by colony-formation assay (Figure 1c). To exclude that Ambra1 protein downregulation during apoptosis was the result of transcriptional modulation, its mRNA levels were determined by quantitative RT-PCR (qRT-PCR). As shown in Supplementary Figure S1a, no modulation of Ambra1 gene expression was observed $8 \mathrm{~h}$ after cell death induction. Then, we evaluated the levels of Ambra1 protein in other cell lines, such as A375, HeLa and Jurkat cells following cell death induction. As reported in Supplementary Figure S1 (b, c and d, respectively), Ambra1 protein downregulation is a common event during apoptosis execution.

To verify whether the observed Ambra1 cleavage was limited to the staurosporine-induced intrinsic apoptotic pathway or occurred also during death receptor-induced extrinsic apoptotic pathway, we stimulated Jurkat cells using TNF $\alpha+$ $\mathrm{CHX}$ and evaluated the levels of Ambra1 protein. As reported in Figure 1d, Ambra1 protein was cleaved also under this experimental condition, thus indicating that its decrease is a general event occurring during apoptosis execution.

We then verified whether staurosporine treatment affected the levels of other autophagic proteins, such as ATG5, the Ambra1-interacting proteins Beclin1 and Vps34, previously described as being cleaved during apoptosis. ${ }^{16,17}$ Neither changes in the total levels of Atg5, Beclin1 and Vps34 nor the appearance of their cleaved fragments were observed during staurosporine-induced cell death, suggesting that Ambra1 is a preferential target of apoptosis-induced proteolysis in the $2 \mathrm{~F}$ cell system (Figure 1a). Interestingly, Beclin1 decrease was observed in Jurkat cells stimulated with both staurosporine or $\mathrm{TNF} \alpha+\mathrm{CHX}$, suggesting that its cleavage could be restricted to specific cell types (Supplementary Figure S1d and Figure 1d respectively).

To address the biological relevance of Ambra1 protein downregulation during apoptosis execution, freshly isolated mouse thymocytes were stimulated $5 \mathrm{~h}$ with Dexamethasone or $8 \mathrm{~h}$ with anti-CD95 agonistic antibody and Ambra1 and Beclin1 protein levels together with PARP cleavage were monitored. As shown in Figure 1e and Supplementary Figure S1e, both Ambra1 and Beclin1 were degraded during apoptosis execution.

During apoptosis, both calpains and caspases are activated, then being required for cell demise. ${ }^{23}$ To verify whether Ambra1 is a target of these proteases during apoptotic execution, 2F cells were incubated for 4 or $6 \mathrm{~h}$ with staurosporine in the presence of calpain $(\mathrm{Cl})$ or caspase (z-VAD-fmk) inhibitors, either singly or in combination. Figure 1f, shows that the staurosporine-mediated Ambra1 decrease was completely prevented only when the two inhibitors were used in combination, suggesting that both caspases and calpains are involved in Ambra1 degradation.

Caspases involvement in Ambra1 degradation prompted us to investigate the presence of Ambra1 cleavage products during apoptosis. In Ambra1 overexpressing 2F cells, staurosporine treatment led to the appearance of specific $\mathrm{N}$-terminal $(\sim 60 \mathrm{kDa}=$ Ambra1 plus myc-tag) and C-terminal $(\sim 100 \mathrm{kDa})$ cleavage products (Figures $2 \mathrm{a}$ and $\mathrm{b}$, respectively). The kinetics of Ambra1 cleavage were similar to those of PARP (Figure 2a, bottom panel), confirming that Ambra1 cleavage occurred simultaneously with caspase activation. Staurosporine-mediated Ambra1 cleavage was inhibited by the caspase inhibitor z-VAD-fmk (Figure 2c). Moreover, a partial inhibition was also observed using a calpain inhibitor 


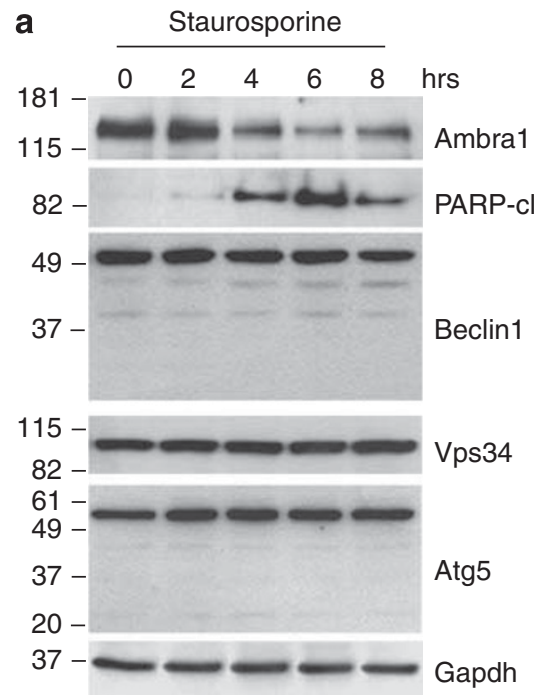

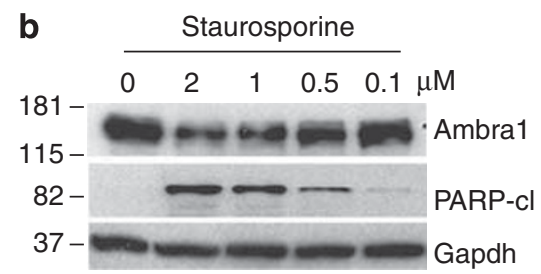

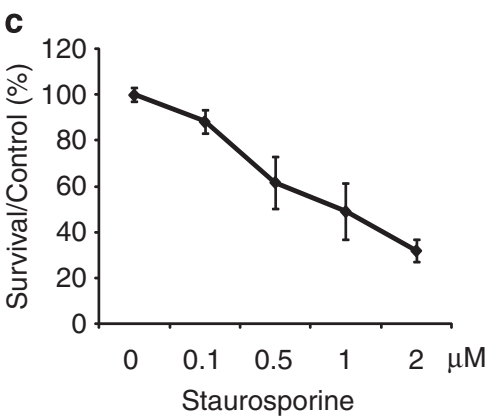

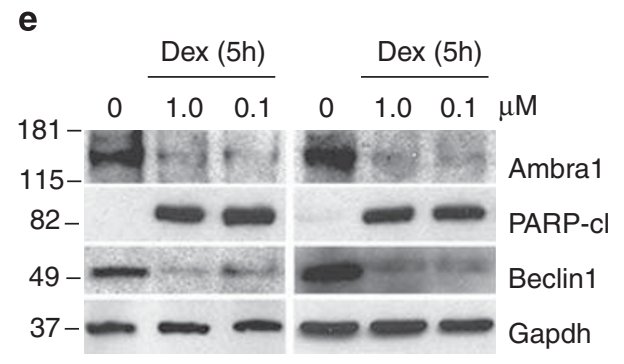

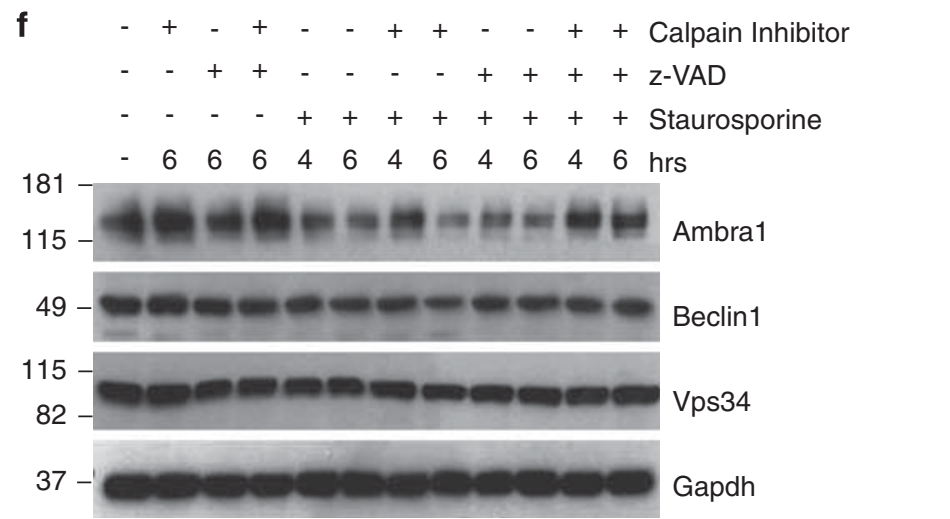

Figure 1 Ambra1 degradation during apoptosis execution. (a) $2 \mathrm{~F}$ cells were incubated with $2 \mu \mathrm{M}$ staurosporine and expression of Ambra1, Beclin1, Vps34 and Atg5 were monitored together with the appearance of cleaved PARP fragment by western blotting in a time-dependent manner, as indicated $(N=3) ;(b) 2 F$ cells were exposed for $6 \mathrm{~h}$ to the indicated decreasing concentration of staurosporine, and Ambra1 and PARP fragment were evaluated by western blotting $(N=3)$. (c) $2 \mathrm{~F}$ cells were treated as in $(\mathbf{b})$ and, plated at limiting dilution, $\left(1: 1 \times 10^{3}, 1: 1 \times 10^{4}\right.$ and $\left.1: 1 \times 10^{5}\right)$ were cultured 2 more weeks and colony-formation assay performed. Data represent average and S.D.'s of three independent experiments $(P<0.05)$. (d) Jurkat cells were treated or untreated $8 \mathrm{~h}$ with human recombinant TNF $\alpha$ plus cycloexymide $(\mathrm{CHX})$, in the presence or absence of $10 \mu \mathrm{M} z$-VAD-fmk and Ambra1, PARP fragment and Beclin1 protein levels were evaluated by western blotting $(N=3)$. (e) Mouse thymocytes were exposed $5 \mathrm{~h}$ to Dexamethasone (Dex) at indicated concentrations and Ambra1 and Beclin1 protein levels together with PARP fragment were evaluated by western blotting. Representative results from 2 of 7 mice are reported. (f) $2 \mathrm{~F}$ cells were incubated $6 \mathrm{~h}$ with $2 \mu \mathrm{M}$ of staurosporine in the presence or absence of $20 \mu \mathrm{M}$ calpain inhibitor (Cl) and/or $10 \mu \mathrm{M}$ caspase pan inhibitor z-VAD-fmk (zVAD) as indicated, and Ambra1 expression analyzed by western blotting $(N=3)$. Gapdh was used as loading control in all reported experiments

(Figure 2d), suggesting a contribution of both types of proteases in Ambra1 cleavage during apoptosis. Interestingly, Ambra1 fragments were not detected under staurosporine treatment at endogenous expression levels (data not shown), this possibly due to their low abundance or short half-life.
Apoptosis-mediated degradation of Ambra1 was not restricted to staurosporine treatment, as we also observed Ambra1 cleavage products using other pro-apoptotic stimuli, such as fenretinide, thapsigargin, tunicamycin and etoposide (Figure 2e). 
a

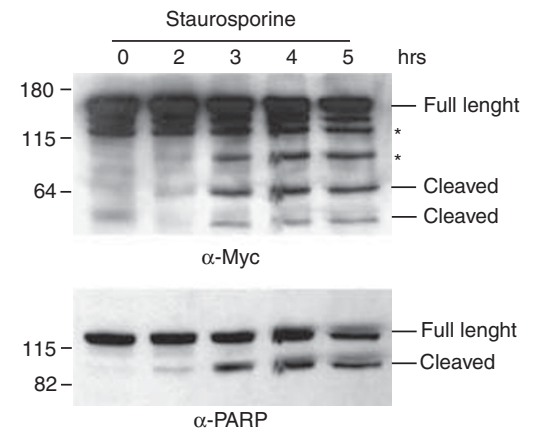

b

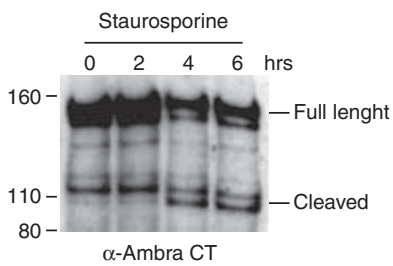

$\alpha$-Ambra CT
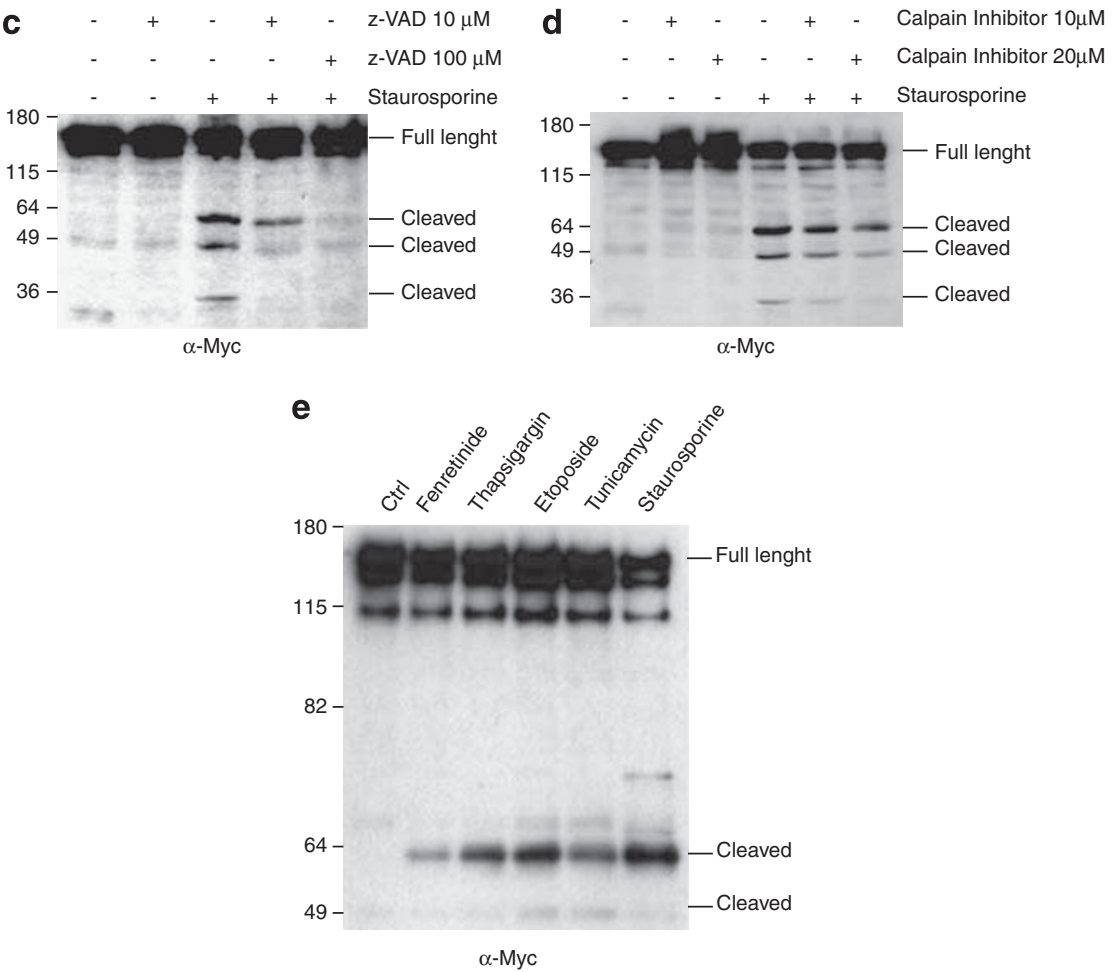

Figure 2 Calpains and caspases are both required for Ambra1 degradation during apoptosis. (a and $\mathbf{b}) 2 \mathrm{~F}$ cells were infected with a retroviral vector encoding myc-Ambra1 and incubated with $2 \mu \mathrm{M}$ staurosporine for indicated time; $\mathrm{N}$-terminal (a, upper panel) and C-terminal (b) fragments of Ambra1 were revealed by using anti-myc or anti-Ambra1 C-terminal specific antibodies, respectively. C-terminal Ambra1 fragment $\approx 100 \mathrm{kDa}$; N-terminal Ambra1 fragment $\approx 60 \mathrm{kDa}=\mathrm{N}$-terminal $(\sim 50 \mathrm{kDa})+$ myc$\operatorname{tag}(10 \mathrm{kDa})$. Apoptosis induction was monitored by determination of PARP cleavage product (a, bottom panel). (* in the upper panel indicate signals resulting from previous antibody incubation of the membrane with an anti PARP antibody). (c and d) Myc-Ambra1-expressing cells were treated with staurosporine (2 $\mu \mathrm{M})$ in the presence or absence of caspase pan inhibitor z-VAD-fmk (zVAD) (10 or $100 \mu \mathrm{M}$, panel c) or calpain inhibitor (Cl) (10 or $20 \mu \mathrm{M}$; panel d) for $6 \mathrm{~h}$ and degradation of Ambra 1 was evaluated by using anti-myc antibody. (e) Cells were incubated with fenretinide $(10 \mu \mathrm{M})$, thapsigargin $(7 \mu \mathrm{M})$, etoposide $(5 \mu \mathrm{g} / \mathrm{ml})$, tunicamycin $(7 \mu \mathrm{M})$ for $18 \mathrm{~h}$ or with staurosporine $(2 \mu \mathrm{M})$ for $6 \mathrm{~h}$ and Ambra1 $\mathrm{N}$-terminal fragments were revealed by an anti-myc antibody. $(N=3)$

On the basis of these results, we conclude that Ambra1 is a target of proteolytic processing during apoptosis and propose that both calpains and caspases are involved in this cleavage event.

\section{Modulation of Ambra1 expression affects cell} susceptibility to apoptosis. To determine the role of Ambra1 protein degradation during apoptosis execution, we decided to evaluate the survival response of $2 \mathrm{~F}$ cell line to cell death stimuli following Ambra1 downregulation. To this end, $2 \mathrm{~F}$ cells were transfected with two Ambra1-specific siRNA oligonucleotides (siAmbra no. 1 and siAmbra no. 2, Figure $3 a$ ) or with non-targeting scrambled siRNA (siCtrl), as a negative control, and treated with staurosporine or etoposide. Cell death was quantified by measuring both the sub-G1 cell population of propidium iodide (PI)-stained cells (Supplementary Figure S2a and b) and Annexin V positive cells, by flow cytometry (Figures $3 b$ and $c$ ) while cell viability was assessed by MTT (3-4,5-dimethylthiazol-2-yl)-2,5diphenyltetrazolium bromide) staining (Figure 3d). Notably, both analyses showed that reduced expression of Ambra1 sensitized cells to both staurosporine- and etoposideinduced cell death in comparison with the scrambled siRNA transfected cells. The reduced survival of Ambra1 downregulated cells following staurosporine treatment were further confirmed by colony-formation assays (Supplementary Figure S2c and d). To exclude that the enhanced susceptibility to cell death was due to other yet 


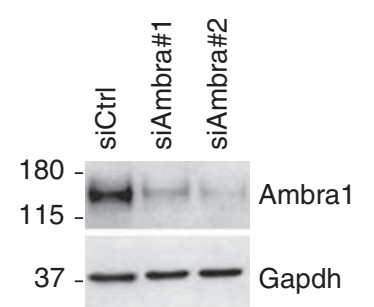

b

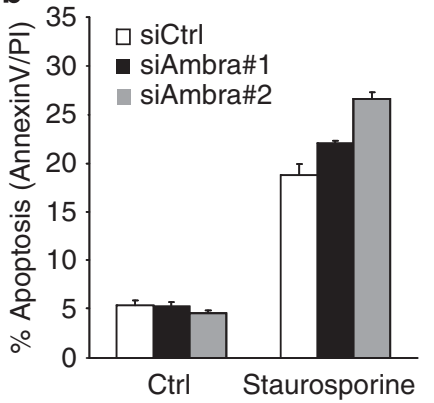

C

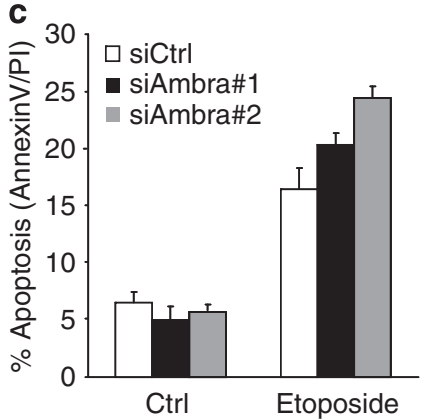

d

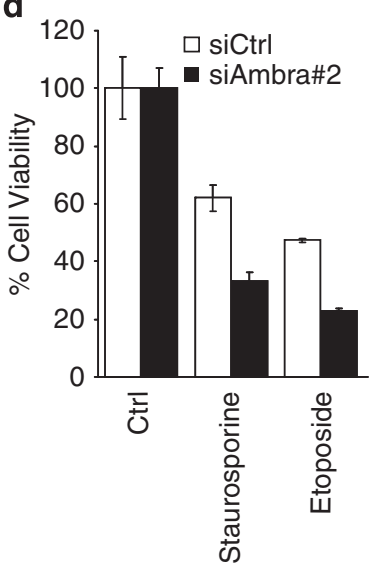

Figure 3 Ambra1 downregulation confers susceptibility to apoptotic cell death. (a-d) Ambra1 expression was downregulated in $2 \mathrm{~F}$ cells by RNA interference using specific oligonucleotides (siAmbra\#1 and siAmbra no. 2; scrambled oligonucletides was used as negative control, siCtrl) and expression levels were revealed by an anti-Ambra1 antibody $(\mathbf{a}, N=3)$. Cells were incubated with staurosporine $(2 \mu \mathrm{M}$, $6 \mathrm{~h})$ or etoposide $(5 \mu \mathrm{g} / \mathrm{ml}, 24 \mathrm{~h})$ and cell death was measured by FACS analysis (b and c, respectively); cell viability was determined by MTT assay (d). Data represent average and S.D.'s of three independent experiments $(P<0.05)$

uncharacterized Ambra1 function besides autophagy, we verified whether the simultaneous downregulation of Ambra1 and the downstream autophagy regulator ATG7 (Supplementary Figure S2e) have similar or additional effects on apoptosis induction. As shown in Supplementary Figure S2f, double transfection of Ambra1 and ATG7 RNA interference oligonucleotides does not increase staurosporine-induced apoptosis when compared with single-oligonucleotide transfections, suggesting that the effect on apoptosis observed upon Ambra1 downregulation was due to autophagy impairment.

These results prompted us to analyse the effect of ectopically expressed Ambra1 on apoptosis induction. 2F cells were transduced with $\beta$-Gal or Ambra1 encoding retroviruses (Figure 4a), and cell death was assessed by $\mathrm{PI}$ staining or MTT assay following staurosporine or etoposide treatment. Compared with cells transduced with the $\beta$-Gal control vector, enforced expression of Ambra1 significantly increased cell viability following cell death stimuli exposure (Figures $4 \mathrm{~b}$ and $\mathrm{c}$ ). The increased survival of Ambra1 overexpressing cells following staurosporine treatment were also verified by colony-formation assays (Supplementary Figure S3a and $b$ ). a
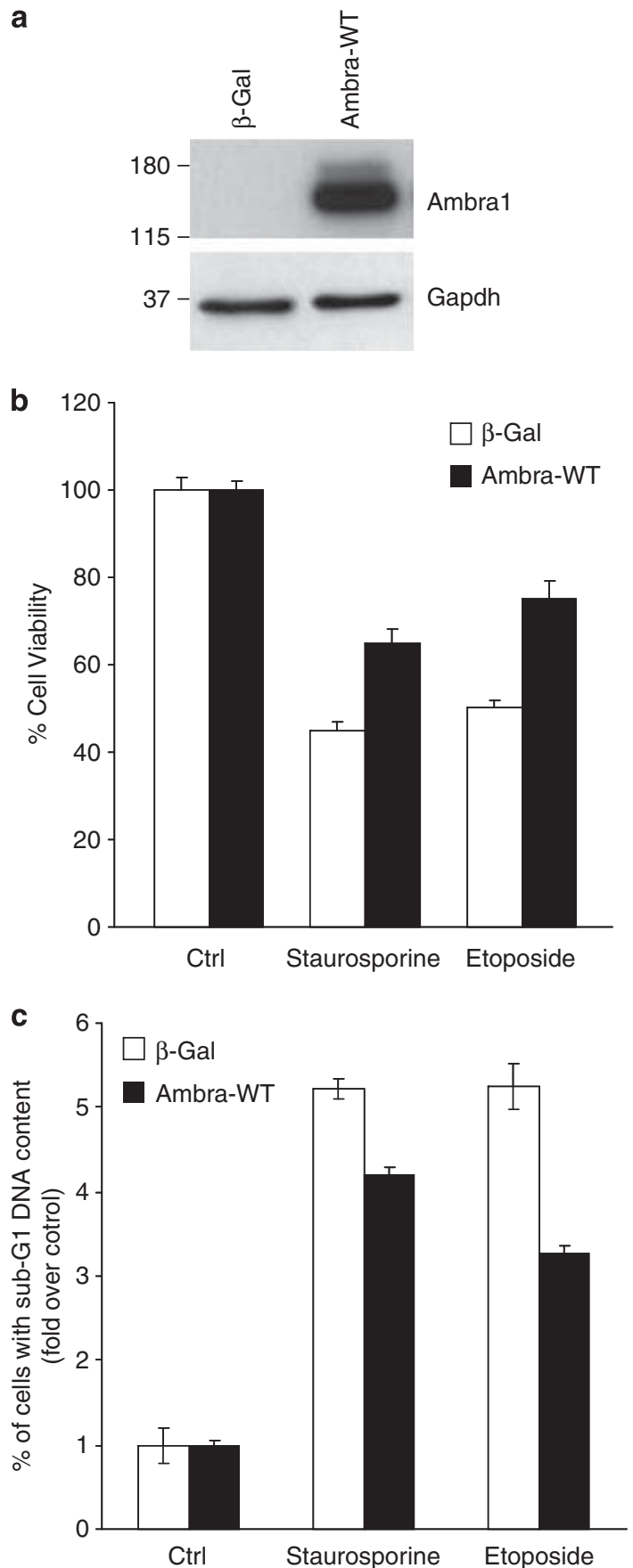

Figure 4 Enforced expression of Ambra1 inhibits apoptosis. (a-c) $2 \mathrm{~F}$ cells were infected with a retroviral vector encoding Flag-Ambra1 or $\beta$-Gal. Protein extracts were analyzed by western blot using anti-Flag (Ambra1) or anti-Gapdh antibodies $(a, N=3)$. Cells were incubated with staurosporine $(2 \mu \mathrm{M}, 6 \mathrm{~h})$ or etoposide $(5 \mu \mathrm{g} / \mathrm{ml}, 24 \mathrm{~h})$, cell viability was evaluated by MTT assay (b) and cell death was measured by FACS analysis (c). Data represent average and S.D.s of three independent experiments $(P<0.05)$

Collectively, these results indicate that Ambra1 functions as a pro-survival factor during apoptosis induction, thus supporting a role of Ambra1 degradation during cell death execution.

Ambra1 cleavage is mediated by caspases at $\mathrm{D}^{482}$. To explore whether Ambra1 is a direct caspase substrate and to 
identify the specific caspase(s) responsible for Ambra1 cleavage, we performed an in vitro caspase-cleavage assay. To this end, in vitro translated ${ }^{35} \mathrm{~S}$-labelled Ambra1 was subjected to cleavage by recombinant active caspase-3, $-6,-7$ and -8 . As shown in Figure $5 a$ and Supplementary Figure S4, all caspases tested were able to cleave Ambra1 with high efficiency, generating several different cleavage products. Two fragments of $\sim 100$ and $\sim 50 \mathrm{kDa}$, present in all digestions, likely represent the fragments detected in apoptotic cells (see Figure 2). SitePrediction in silico analysis $^{24}$ of the Ambra1 protein sequence revealed several putative caspase recognition sites (Supplementary Table. 1). Taking into account the high preference for certain cleavage sites and the predicted size of the generated fragments, we have focused our research on the TESD ${ }^{482} \mathrm{G}$
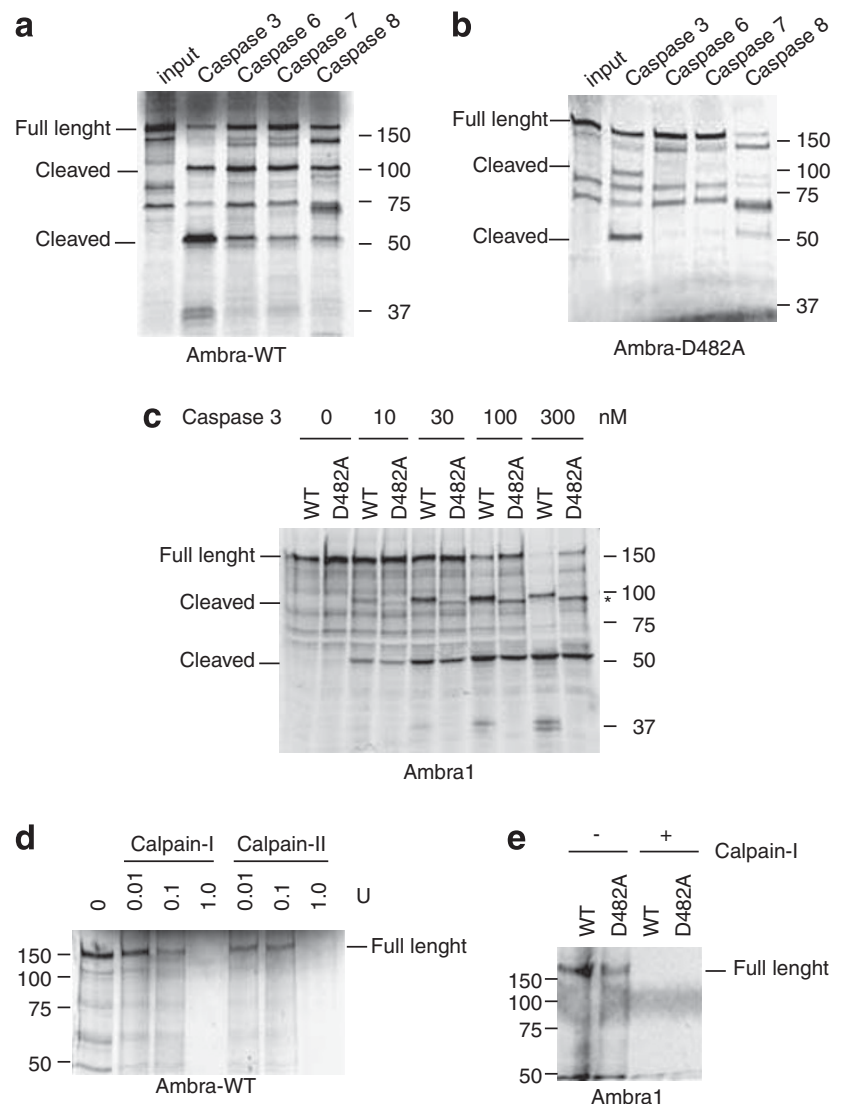

Figure 5 Ambra1 is a caspase and calpain substrate. Radioactively labeled recombinant Ambra1-WT (a) or Ambra1-D482A mutant (b) was subjected to an in vitro caspase-cleavage assay by using recombinant active caspase-3, $-6,-7$ or -8 . Samples were subjected to SDS-PAGE and protein fragments visualized by autoradiography. (c) Caspase-3 cleavage of radioactively labelled recombinant Ambra1-WT and Ambra1-D482A mutant. ( ${ }^{*}$ points to Ambra1-D482A mutant protein fragment with apparent slightly different molecular weights compared with wild-type protein, likely due to alternative cleavage). (d) Radioactively labeled recombinant Ambra1 was subjected to an in vitro calpain-cleavage assay by using recombinant active calpain-I and -II. Samples were subjected to SDS-PAGE and protein fragments visualized by autoradiography $(N=3)$. (e) Radioactively labeled recombinant Ambra1-WT or Ambra1-D482A mutant were subjected to an in vitro calpain-cleavage assay by using recombinant active calpain-I. Samples were subjected to SDS-PAGE and protein fragments visualized by autoradiography $(N=3)$ site. To verify whether caspase cleavage indeed occurred at $\mathrm{TESD}^{482} \mathrm{G}$, we generated an Ambra1 mutant carrying a single-point mutation $\left(D^{482} \rightarrow A\right)$ in order to disrupt the predicted putative caspase cleavage site. As shown in Figure $5 \mathrm{~b}, \mathrm{D}^{482}$ to $A$ substitution completely abrogated the generation of both the 100- and 50-kDa Ambra1 fragments by caspase- $6,-7$ and -8 , as compared with Ambra1 wild type (WT). By contrast, mutation of $D^{482}$ apparently did not prevent cleavage by caspase-3. However, direct comparison of the caspase-3-cleavage pattern of Ambra1 ${ }^{\mathrm{WT}}$ and Ambra $1^{\mathrm{D} 482 \mathrm{~A}}$ revealed that the fragments obtained with the Ambra1 mutant have a molecular weight which is slightly different when compared with the WT protein, possibly due to alternative cleavage sites being recognized by the caspase 3 when the D482 is mutated (Figure $5 \mathrm{c}$ ). We also performed an in vitro calpain-cleavage assay to test whether calpains are directly involved in Ambra1 proteolysis. To this end, in vitro translated ${ }^{35} \mathrm{~S}$-labelled Ambra1 was subjected to cleavage by recombinant active calpain-I and -II. As shown in Figure 5d, Ambra1 was completely degraded by both calpains, indicating that calpains are able to directly target Ambra1 and suggesting that they may be responsible for its complete loss during apoptosis. In line with this result, D482A mutation does not interfere with the calpain-dependent cleavage of Ambra1 (Figure 5e).

To verify that TESD ${ }^{482} \mathrm{G}$ sequence in Ambra1 is the target for caspase cleavage in cells committed to die, we stably expressed Ambra $1^{\mathrm{WT}}$ and Ambra $1^{\mathrm{D} 482 \mathrm{~A}}$ mutant in $2 \mathrm{~F}$ cells. No detectable cleavage products of Ambra ${ }^{\mathrm{D} 482 \mathrm{~A}}$ mutant were observed when cells were incubated with staurosporine, confirming that this sequence is responsible for Ambra1 cleavage (Figures $6 a$ and $b$ ); likewise no alternative cleavages seemed to occur in vivo when this site was mutated. To exclude that the lack of cleavage was due to a misplacement of the mutant Ambra1, we also verify that Ambra1 ${ }^{\text {WT }}$ and Ambra1 ${ }^{\mathrm{D} 482 \mathrm{~A}}$ display a similar subcellular distribution (Supplementary Figure S3c). a

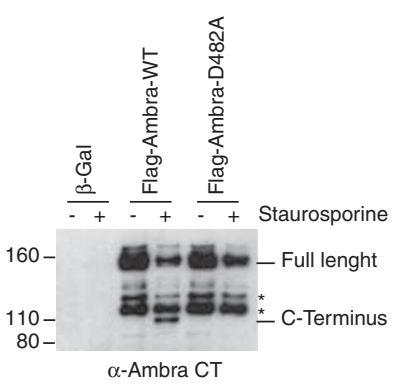

b

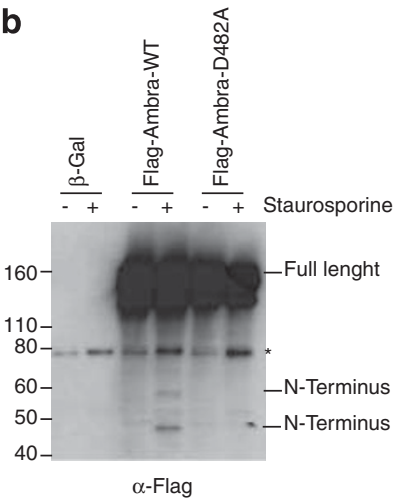

Figure 6 Ambra1 is cleaved in vivo at D482 by caspases. (a) $2 \mathrm{~F}$ cells were infected with a retrovirus encoding $\beta$-Gal, carboxy-terminal Flag-tagged Ambra1WT (Ambra1-WT-Flag) or carboxy-terminal Flag-tagged Ambra1-D482A (Ambra1D482A-Flag). Cells were incubated with $2 \mu \mathrm{M}$ staurosporine for $6 \mathrm{~h}$ and protein extracts analyzed by western blot using anti-Flag antibody $(N=3)$. (b) $2 \mathrm{~F}$ cells were infected with a retrovirus encoding $\beta$-Gal, amino-terminal Flag-tagged Ambra1-WT (Flag-Ambra1-WT) or amino-terminal Flag tagged Ambra1-D482A (Flag-Ambra1D482A). Cells were incubated with $2 \mu \mathrm{M}$ staurosporine for $6 \mathrm{~h}$ and protein extracts analyzed by western blot using anti-Flag antibody ( ${ }^{*}$ aspecific band, $N=3$ ) 
As the protein cleavage of other autophagic factors during cell death execution generates protein fragments with proapoptotic function and mitochondrial localization, ${ }^{14-17,26,27}$ we transduced $2 \mathrm{~F}$ cells with retroviral vectors encoding the N-terminal (1-482 aa) and C-terminal (482-1300 aa) Ambra1 fragments and analyzed their activity in relation to apoptosis. We observed that Ambra1 C-terminal fragment has a cellular distribution similar to the full length (WT) (Supplementary Figure S5a and b) and did not modulate the rate of apoptosis when ectopically expressed (Supplementary Figure S5c and d). Instead, the Ambra1 $\mathrm{N}$-terminal fragment seems to be highly unstable, since it was undetectable when ectopically expressed (Supplementary Figure S5c). Collectively, these data suggest that Ambra1 cleavage products, in contrast to other autophagic factors, have no pro-apoptotic functions.

\section{Caspase-uncleavable Ambra1 confers higher resistance} to stress-induced cell death. To elucidate whether caspase-mediated degradation of Ambra1 has a role in the execution of apoptosis, Ambra1 ${ }^{\mathrm{WT}}$ or Ambra1 ${ }^{\mathrm{D} 482 \mathrm{~A}}$ mutant was stably expressed in $2 \mathrm{~F}$ cells (Figure 7a) and cell death induced by staurosporine or etoposide treatment was evaluated by FACS analysis of sub-G1 DNA content (Figure 7b). Notably, Ambra1 ${ }^{\mathrm{D} 482 \mathrm{~A}}$ over-expression was more effective than wild-type Ambra1 in protecting cells against staurosporine- or etoposide-induced apoptosis. The increased protective role of Ambra-D481A to staurosporine treatment was also confirmed by colonyformation assay (Supplementary Figure S3 a and b).

We then investigated whether the higher pro-survival function of caspase-uncleavable Ambra1 could be attributed to its ability to sustain autophagy for a longer time compared with the WT protein. To this end, we evaluated the autophagy induction in staurosporine-treated cells by measuring the degradation rate of the autophagy reporter p62-GFP. ${ }^{25}$ This analysis was preferred to GFP-LC3 dot count because the quantification of the latter was hampered by the significant morphological changes caused by staurosporine. p62-GFPexpressing $2 \mathrm{~F}$ cells were transduced with $\beta$-Gal, Ambra1 ${ }^{\mathrm{WT}}$ or Ambra $1^{\mathrm{D} 482 \mathrm{~A}}$ by retroviral infection. Cells were treated with staurosporine and autophagy determined by FACS analysis at the indicated time points. As shown in Figure 7c, autophagy was induced in all cell lines at early time points ( 0 to $4 \mathrm{~h}$ ) post treatment but at higher levels in both Ambra1 ${ }^{\mathrm{WT}}$ - and Ambra $1^{\mathrm{D} 482 \mathrm{~A}}$-expressing cells. After $4 \mathrm{~h}$ of staurosporine treatment, we observed no further induction of autophagy in both $\beta$-Gal and Ambra1 ${ }^{\text {WT }}$ cells, this correlating with the activation of caspases and cleavage of both endogenous or ectopic Ambra1 (Figures 1a and 2). By contrast, autophagymediated p62 degradation was still observed in Ambra $1^{\text {D482A }}$ expressing cells after $4 \mathrm{~h}$ post treatment, thus correlating with a more efficient apoptosis inhibition of the caspase uncleavable Ambra1 mutant. Indeed, time-course analysis of Ambra1 WT or D482A levels following staurosporine treatment showed that the $D^{482} \rightarrow A$ mutation partially prevents apoptosis-induced Ambra1 decrease (Figure 7d).

Collectively, these results support for a role of Ambra1 degradation in shutting down the pro-survival functions of autophagy during stress-induced cell death.
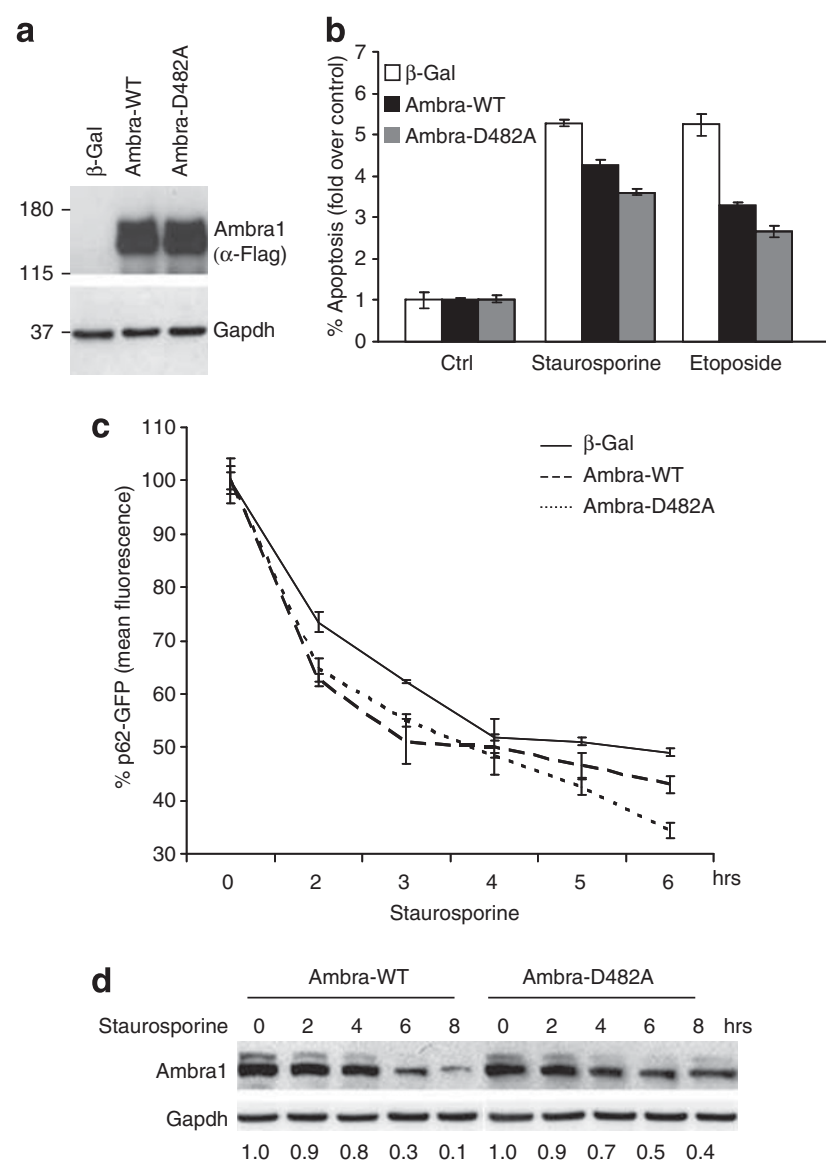

Figure 7 Apoptosis susceptibility correlates with autophagy induction. (a-c) $2 \mathrm{~F}$ cells were infected with a retroviral vector encoding Flag-Ambra1-WT, Flag-Ambra1$\mathrm{D} 482 \mathrm{~A}$ or $\beta$-Gal and protein expression was revealed by western blot by using antiFlag antibody (a). $N=3$. Cells were treated with staurosporine $(2 \mu \mathrm{M}, 6 \mathrm{~h})$ or etoposide $(5 \mu \mathrm{g} / \mathrm{ml}, 24 \mathrm{~h})$ and apoptosis was evaluated by FACS analysis (b). Data represent average and S.D.s of three independent experiments $(P<0.05)$. (c) $\beta$-Gal, FlagAmbra1-WT- and Flag-Ambra1-D482A-expressing cells were infected with a retroviral vector encoding p62-GFP fusion protein, treated with staurosporine $(2 \mu \mathrm{M})$ and autophagy analyzed by evaluating the expression of p62-GFP by FACS analysis, at indicated time points. Data represent average and S.D.S of three independent experiments $(P<0.05)$. (d) Flag-Ambra1-WT- and Flag-Ambra1-D482A-expressing cells were treated with staurosporine $(2 \mu \mathrm{M})$ and Ambra1 levels were monitored by western blotting at the indicated times. $(N=3)$. The blot was subjected to a densitometry analysis as described in the Experimental procedures section. The numbers indicated below represent the average density (in arbitrary units) detected by the analysis software. Gapdh was used as loading control

\section{Discussion}

Under stressful cellular conditions, pro-survival and pro-death processes are concomitantly activated, the final outcome depending on the complex crosstalk between these pathways. $^{1,11}$ The inhibition of autophagy by the apoptotic machinery has been proposed as one of the crucial events responsible for the irreversible switch from survival to death. ${ }^{14-17}$ In the current study, we show that Ambra1 proteolytic degradation during the early phases of apoptosis by caspases and calpains contributes to the abrogation of the pro-survival function of autophagy.

Our findings are consistent with recent studies showing that other autophagic proteins such as Beclin1, Vps34, Atg4D, 
Atg5 and Vps34 are targets of apoptotic proteases. ${ }^{14-17,26,27}$ These data strengthen the emerging view that autophagy impairment by apoptotic machinery could represent a 'point of no return' toward death. However, while protease-mediated cleavage of Beclin1, Atg4D and Atg5 produce truncated proteins acquiring a pro-apoptotic function, ${ }^{14-17,26,27}$ Ambra1 cleavage seems to precede a complete protein degradation rather than fragment accumulation. In vitro caspase cleavage assay confirmed that Ambra1 is a substrate of different caspases and allowed us to identify $D^{482}$ as a major caspase cleavage site in Ambra1. Significantly, a $D^{482} \rightarrow A$ Ambra1 mutation prevented cleavage product formation in vivo and protected cells from apoptosis more efficiently than the WT protein did. On the other hand, no enhancement of staurosporine-induced apoptosis was observed when caspase-generated Ambra1 fragments were independently expressed in cells (data not shown); this suggests that Ambra1 cleavage products, in contrast to other autophagic factors, have no pro-apoptotic functions. ${ }^{14-17,26,27}$ Differently from caspases, calpains completely degrade Ambra1 in an in vitro assay, thus possibly explaining the decrease of Ambra1 protein levels in vivo following apoptosis induction. The fact that Ambra1 decline could be prevented only by concomitant inhibition of calpains and caspases and that a caspase uncleavable Ambra1 mutant is partially resistant to staurosporine-induced degradation seems to confirm that these proteases may function either in concert or independently to ensure Ambra1 removal during apoptosis.

The contribution of Ambra1 degradation to the apoptotic process was confirmed by RNA interference approaches, showing that Ambra1 downregulation markedly sensitized cells to staurosporine- or etoposide-induced cell death. The pro-survival role for Ambra1 was further substantiated by the enhanced resistance to apoptosis of Ambra1 over-expressing cerebellar granule neurons induced to die by trophic factor withdrawal, ${ }^{21}$ as well as by the excessive apoptosis observed in selected areas of the developing brain in Ambra1 mutant mice. ${ }^{19}$ Apoptosis contributes to the morphogenesis of central nervous system by participating in both the selection of neural precursors and the competition of post-mitotic neurons for their cellular targets. ${ }^{28}$ In the light of our results, it would be interesting to analyze whether Ambra1 protein degradation has a functional role in triggering cell death of neuronal cells during embryonic development.

Autophagy impairment has been demonstrated in several neurodegenerative disorders such as in spinocerebellar ataxia and in Parkinson's, Alzheimer's, and Huntington's disease. ${ }^{29-32}$ These pathologies are indeed characterized by intracellular cytotoxic aggregates, calcium imbalance and calpain and caspase activation. Recently, it has also been reported that autophagy inhibition could be due to caspasemediated Beclin1 cleavage in Alzheimer's disease. ${ }^{26}$ Sublethal activity of caspase- 6 and caspase- 7 has also been linked to the onset and progression of Alzheimer and SCA pathologies. ${ }^{29,31}$ Given the functional relationship between Ambra1 levels and caspase activation, an important step forward could be to evaluate the potential value of Ambra1 as a diagnostic or prognostic marker in neurodegenerative disorders and to elucidate the Ambra1 degradation as possible contribution to the onset/progression of these pathologies.

\section{Materials and Methods}

Cell culture and treatments. The $2 \mathrm{~F}$ cell line and Jurkat $\mathrm{T}$ cell line were cultured in Dulbecco's modified Eagle's medium (Sigma-Aldrich, St. Louis, MO, USA) or RPMI-1640 medium, respectively, supplemented with $10 \%$ fetal bovine serum (FBS, Sigma-Aldrich), $2 \mathrm{mM}$ L-glutamine (Sigma-Aldrich), 1\% penicillin/ streptomycin solution (Sigma-Aldrich) at $37{ }^{\circ} \mathrm{C}$ under $5 \% \mathrm{CO}_{2}$. Cells were treated with thapsigargin and tunicamycin (Sigma-Aldrich) at a final concentration of $7 \mu \mathrm{g} /$ $\mathrm{ml}$, etoposide (Sigma-Aldrich) at $5 \mu \mathrm{g} / \mathrm{ml}$, staurosporine (Sigma-Aldrich) at $2 \mu \mathrm{M}$ (or other concentration, when indicated), Fenretinide (Janssen-Cilag Ltd, Basserdorf, Switzerland) at $10 \mu \mathrm{M}$, human recombinant TNF $\alpha$ (R\&D Systems Inc., Minneapolis, $\mathrm{MN}, \mathrm{USA}$ ) at $10 \mathrm{ng} / \mathrm{ml}$, Rapamycin (Sigma-Aldrich) at $1 \mu \mathrm{M}$, as indicated in the figure legends. The above-mentioned agents were added in DMSO with an equal volume of vehicle used to treat control cells $(0.1-0.5 \%$ DMSO). When indicated, cells were incubated with 10 or $100 \mu \mathrm{M}$ caspase pan-inhibitor (Z-VAD-fmk; Alexis Biochemicals, San Diego, CA, USA), and 10 or $20 \mu \mathrm{M}$ calpain pan-inhibitor (Cl; N-acetyl-Leu-Leu-Norleu-al; Sigma-Aldrich).

Thymocytes obtained from BALB/CN mice (4-6-week-old) were washed once in RPMI-1640 medium, passed through a nylon mesh, and resuspended in complete medium (RPMI-1640 medium supplemented with 10\% heat-inactivated FBS, (Sigma-Aldrich), $2 \mathrm{mM}$ L-glutamine (Sigma-Aldrich), 1\% penicillin/streptomycin solution (Sigma-Aldrich)) at $37^{\circ} \mathrm{C}$ under $5 \% \mathrm{CO}_{2}$. Thymocytes were cultured at $10^{6} \mathrm{cell} / \mathrm{s} / \mathrm{ml}$ in 24-well plates for either 5 or $6 \mathrm{~h}$ in the presence or absence of Dexamethasone (Dex; 1,0 or $0,1 \mu \mathrm{M}$; Sigma-Aldrich) or agonistic anti-CD95 Ab (100 ng/ml; ENZO Life Sciences AG, Lausen, Switzerland), respectively.

RNA interference. siRNA oligoribonucleotides corresponding to the human Ambra1 CDNA sequences were purchased from Dharmacon (Dharmacon Inc., Lafayette, CO, USA).

Ambra1 siRNA no. 1: 5'-AGAACTGCAAGATCTACAA-3'

Ambra1 siRNA no. 2: 5'-GGCCTATGGTACTAACAAA-3'

siRNA oligonucleotides corresponding to the human ATG7 cDNA sequences were purchased from Invitrogen (Invitrogen, Carlsbad, CA, USA).

ATG7 siRNA: 5'-GCCAGTGGGTTTGGATCAAAGGTTT-3'

$25 \times 10^{4} \mathrm{cells} /$ well were transfected with $100 \mathrm{pmol}$ siRNA in six-well plates by using Lipofectamine RNAi Max (Invitrogen) as indicated by the supplier. Transfection was repeated on two consecutive days to increase transfection efficiency. $24 \mathrm{~h}$ after last transfection, cells were plated at $25 \times 10^{4}$ cells/well in six-well plates and treated with the indicated agents. RNA decrease was checked by quantitative qRT-PCR and western blotting, $48 \mathrm{~h}$ after transfection.

qRT-PCR. RNA was extracted by using Trizol reagent (Invitrogen) as indicated by the supplier. CDNA synthesis was generated using a reverse transcription kit (Promega, Madison, WI, USA) according to the manufacturer's recommendations. Quantitative PCR reactions were performed with the LightCycler (Roche, Nutley, NJ, USA) thermocycler, as previously described. ${ }^{33}$ Primer sets for all amplicons were designed using the Primer-Express 1.0 software system (Roche):

L34 forward: 5'-GTCCCGAACCCCTGGTAATAGA-3'

L34 reverse: $5^{\prime}$-GGCCCTGCTGACATGTTTCTT-3'

Ambra1 forward: 5'-AACCCTCCACTGCGAGTTGA-3'

Ambra1 reverse: $5^{\prime}$-TCTACCTGTTCCGTGGTTCTCC-3'

ATG7 forward: 5'-GCGGCAAGAAATAATGGCG-3'

ATG7 reverse: $5^{\prime}$-TTCTGGGTCAACTCATGCCAA- $3^{\prime}$

L34 mRNA level was used as an internal control and results were expressed as previously described. $^{33}$

Western blotting. Total proteins were extracted from cells by using the Cell Lytic buffer (Sigma-Aldrich) following addition of protease inhibitors and resolved by electrophoresis through NuPAGE Bis-Tris gel (Invitrogen) and electroblotted onto nitrocellulose (Protran, Schleicher \& Schuell, Dassel, Germany) membrane. Blots were incubated with indicated primary antibodies in $5 \%$ non-fat dry milk in PBS plus $0.1 \%$ Tween 20 overnight at $4{ }^{\circ} \mathrm{C}$.

Primary antibodies were: rabbit polyclonal anti-myc Tag antibody $(1: 500$; Upstate Biotechnology, Lake Placid, NY, USA), goat anti-Beclin1 (1:500; BectonDickinson, Mountain View, CA, USA), rabbit anti-Ambra1 (1:2000; Strategic Diagnostic Inc. or Covalab, Cambridge, UK), mouse monoclonal anti-Gapdh

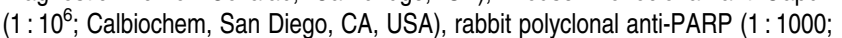
Cell Signaling, Danvers, MA, USA), rabbit polyclonal anti-PARP cleaved (1:1000; Cell Signaling), mouse monoclonal anti-Flag (1:3000; Sigma-Aldrich), rabbit polyclonal anti-Vps34 (1:1000; Invitrogen) and mouse monoclonal anti-Atg5 
(1:500; Cell Signaling, Carlsbad, CA, USA). Detection was achieved using horseradish peroxidase-conjugate secondary antibody $(1: 5000$; Jackson Immuno Research, West Grove, PA, USA) and visualized with ECL plus (Amersham Biosciences, Buckinghamshire, UK). To quantify band intensity, western blot images were analyzed densitometrically using a charge-coupled device camera (GelDoc 2000, Bio-Rad, Hercules, CA, USA) and processed with the QuantyOne software (Bio-Rad)

cDNA cloning. For retroviral expression, all constructs were cloned in PCLPCX vector. ${ }^{33}$ Myc-tag full-length Ambra1 vector was previously described. ${ }^{33}$ The CDNA encoding the Ambra1-D ${ }^{482}$ A mutant was constructed by site-directed PCR mutagenesis (Promega). WT and Ambra1- $D^{482} A$ mutant were cloned in frame with either a N-terminal or a C-terminal Flag-tag. Ambra1 C-terminal or N-terminal was amplified by PCR, using specific primers. Ambra1 fragments were cloned in frame with a N-terminal Flag-tag. The sequences of all PCR-amplified cDNAs were verified by DNA-sequencing analysis.

Retrovirus generation and infection. Fifteen $\mu \mathrm{g}$ of the retroviral vectors were co-transfected with $5 \mu \mathrm{g}$ of an expression plasmid for the vesicular stomatitis virus $\mathrm{G}$ protein into a cell line $293 \mathrm{gp} / \mathrm{bsr}$ by using the calcium phosphate method. $48 \mathrm{~h}$ later, the supernatant containing the retroviral particles was recovered and supplemented with polybrene $(4 \mu \mathrm{g} / \mathrm{ml})$. Cells were infected by incubation with retroviral containing supernatant for $6-8 \mathrm{~h} .{ }^{19}$

In vitro transcription/translation. The plasmids $\mathrm{PCLPCX}-\mathrm{Ambra} 1^{\mathrm{WT}}$ and pCLPCX-Ambra1 ${ }^{\text {D482A }}$ were used as a template for in vitro coupled transcription/ translation in a rabbit reticulocyte lysate system according to the manufacturer's instructions (Promega). For detection of the translation products, ${ }^{35} \mathrm{~S}$-methionine was added to the translation reactions. For caspase-cleavage assay, recombinant caspase- $3,-6,-7$ and -8 were generated as described. ${ }^{34}$ Translation reactions $(2 \mu \mathrm{l}$ each) were incubated with $300 \mathrm{nM}$ recombinant caspase-3, -6, -7 and -8 in $24 \mu \mathrm{l}$ of cell-free system buffer (10 mM HEPES- $\mathrm{NaOH}$ pH 7.4, $220 \mathrm{mM}$ mannitol, $68 \mathrm{mM}$ sucrose, $2 \mathrm{mM} \mathrm{MgCl}$, $5 \mathrm{mM}$ pyruvate, $0.1 \mathrm{mM} \mathrm{PMSF}, 200 \mathrm{U} / \mathrm{ml}$ aprotinin, $10 \mathrm{mg} / \mathrm{ml}$ leupeptin) for $1 \mathrm{~h}$ at $37^{\circ} \mathrm{C}$. The cleavage products were analyzed by SDS-PAGE and autoradiography. For calpain-cleavage assay, translation reactions $(2 \mu \mathrm{l}$ each) were incubated with $0.01 \mathrm{U}, 0.1 \mathrm{U}$ or $1 \mathrm{U}$ of recombinant calpain-I (human; Calbiochem) or -II (rat; Calbiochem) in $24 \mu \mathrm{l}$ of buffer (100 mM Hepes, $\mathrm{pH}: 7,5,10 \%$ glycerol, $1 \mathrm{mM} \mathrm{DTT}$, and 5 or $10 \mathrm{mM} \mathrm{CaCl}_{2}$ ) for $15 \mathrm{~min}$ at $37^{\circ} \mathrm{C}$ The cleavage products were analyzed by SDS-PAGE and autoradiography.

Cell-viability assay. Cell viability was measured by 3-(4,5-dimethylthiazol-2yl)-2,5-diphenyltetrazolium bromide (MTT) assay. Cells were plated at a concentration of $8.4 \times 10^{3}$ cells/well in 96-well plates with $100 \mu \mathrm{l}$ medium and grown for $24 \mathrm{~h}$. Cells were treated as indicated and incubated with $0.5 \mathrm{mg} / \mathrm{ml} \mathrm{MTT}$ in PBS for $3 \mathrm{~h}$ at $37^{\circ} \mathrm{C}$. After an additional $15 \mathrm{~min}$ of incubation with $100 \mu \mathrm{l}$ of DMSO at room temperature, absorbance values at $570 \mathrm{~nm}$ were determined with a microplate reader (TECAN, Grödig, Austria). Experiments were repeated independently 3 times.

Autophagy assay. Cells co-infected with a retroviral vector encoding p62-GFP and mCherry were plated at a concentration of $25 \times 10^{4}$ cells/well in six-well plates and treated as indicated. Cells were fixed in $4 \%$ paraformaldehyde and fluorescence was analyzed by FACS analysis. The GFP mean fluorescence values were corrected with mCherry fluorescence used as an internal control. Experiments were repeated independently three times.

Apoptosis analysis. Flow cytometry of fixed and PI-stained cells was used to estimate the level of cell death (cells with sub-G1 DNA content), as previously described. ${ }^{33}$ Flow cytometry of Annexin V/PI stained cells have been used to estimate apoptotic cells. Briefly, $2 \times 10^{5}$ cells were resuspended in $0.4 \mathrm{ml}$ binding buffer (10 mM HEPES/ $\mathrm{NaOH}$, pH 7.4; $140 \mathrm{mM} \mathrm{NaCl} ; 2.5 \mathrm{mM} \mathrm{CaCl}_{2}$ ). Annexin V has been added to a final concentration of $2.5 \mu \mathrm{g} / \mathrm{ml}$ and cells incubated for $10 \mathrm{~min}$ in the dark. Cells were washed twice in binding buffer, resuspended in $0.4 \mathrm{ml}$ binding buffer, PI was added to a final concentration of $5 \mu \mathrm{g} / \mathrm{ml}$ and analyzed by FACS.

Confocal microscopy. Cells were grown on coverslips and fixed with $4 \%$ PFA in PBS followed by permeabilization with $0.1 \%$ Triton X-100 in PBS. Primary antibodies were incubated for $1 \mathrm{~h}$ at RT and visualized by means of AlexaFluor488 (Invitrogen) and Cy3-conjugated secondary antibodies (Invitrogen). Coverslips were mounted in antifade (SlowFade; Invitrogen) and examined under a confocal microscope (TCS SP2; Leica, Wetzlar, Germany) equipped with a $63 \times 1.40-0.60$ NA HCX Plan Apo oil BL objective at RT.

Colony-formation assay. Cells were plated at limiting dilution concentration $\left(1: 1 \times 10^{3}, 1: 1 \times 10^{4}\right.$ and $\left.1: 1 \times 10^{5}\right)$ and cultured for 2 weeks. Cells were washed twice in PBS and fixed in cold Methanol $\left(-20^{\circ} \mathrm{C}\right)$. Cell colony were stained by using $5 \%$ Giemsa (MERCK KGaA, Darmstadt, Germany) solution and incubated $20 \mathrm{~min}$ at rt. Dishes were washed twice in $\mathrm{ddH}_{2} \mathrm{O}$, dried and colony were counted.

Statistical analysis. Microsoft Excel was used for statistical analysis. Statistical significance was determined using the Student's $t$-test. A $P$-value of equal to or less than 0.05 was considered significant.

\section{Conflict of Interest}

The authors declare no conflict of interest.

Acknowledgements. We thank Dr. A Bredan for editing the paper. This work was supported by a grant from European Community (APO-SYS Health F4-2007200767) to MP, Ministry for Health of Italy ('Ricerca Corrente' to MP and GMF, 'Ricerca Finalizzata RF07.103' to GMF and 'Ricerca Oncologica n. ONC-ORD 35/ 07' to GMF), AIRC and Compagnia di San Paolo di Torino to MP, AIRC (MFAG11743 ) to MC. SL holds a postdoctoral fellowship from the FWO. The doctoral fellowship of EW has been supported by Ghent University grants (BOF 2001-GOA 12050502 en BOF 2005-GOA 01GC0205) and by the Flemish Government Methusalem project BOF09/01M00709. Research in the Vandenabeele group is funded by European grants (FP6 ApopTrain, MRTN-CT-035624; FP7 EC RTD Integrated Project, Apo-Sys, FP7-200767; Euregional PACT II), Belgian grants (Interuniversity Attraction Poles, IAP 6/18), Flemish grants (Research Foundation Flanders, FWO G.0875.11 and FWO G.0973.11), Ghent University grants (MRP, GROUP-ID consortium) and grants from Flanders Institute for Biotechnology (VIB). PV holds a Methusalem grant (BOF09/01M00709) from the Flemish Government. FC is partly supported by the Associazione Italiana per la Ricerca sul Cancro (AIRC), the Telethon Foundation, the Italian Ministry of Health and the Italian Ministry of University and Research.

1. Lum JJ, DeBerardinis RJ, Thompson CB. Autophagy in metazoans: cell survival in the land of plenty. Nat Rev Mol Cell Biol 2005; 6: 439-448.

2. Xie Z, Klionsky DJ. Autophagosome formation: core machinery and adaptations. Nat Cell Biol 2007; 9: 1102-1109.

3. Shintani T, Klionsky DJ. Autophagy in health and disease: a double-edged sword. Science 2004; 306: 990-995.

4. Yu L, Alva A, Su H, Dutt P, Freundt E, Welsh $S$ et al. Regulation of an ATG7-beclin 1 program of autophagic cell death by caspase-8. Science 2004; 304: 1500-1502.

5. Shimizu S, Kanaseki T, Mizushima N, Mizuta T, Arakawa-Kobayashi S, Thompson CB et al. Role of Bcl-2 family proteins in a non-apoptotic programmed cell death dependent on autophagy genes. Nat Cell Biol 2004; 6: 1221-1228.

6. Gozuacik D, Kimchi A. Autophagy as a cell death and tumor suppressor mechanism. Oncogene 2004; 23: 2891-28906.

7. Lee CY, Baehrecke EH. Steroid regulation of autophagic programmed cell death during development. Development 2001; 128: 1443-1455.

8. Mills KR, Reginato M, Debnath J, Queenan B, Brugge JS. Tumor necrosis factor-related apoptosis-inducing ligand (TRAIL) is required for induction of autophagy during lumen formation in vitro. Proc Natl Acad Sci U S A 2004; 101: 3438-3443.

9. Ogier-Denis E, Codogno P. Autophagy: a barrier or an adaptive response to cancer. Biochim Biophys Acta 2003; 1603: 113-128.

10. Fimia GM, Piacentini M. Regulation of autophagy in mammals and its interplay with apoptosis. Cell Mol Life Sci 2010; 67: 1581-1588.

11. Maiuri MC, Le Toumelin G, Criollo A, Rain JC, Gautier F, Juin P et al. Functional and physical interaction between $\mathrm{Bcl}-\mathrm{X}(\mathrm{L})$ and a BH3-like domain in Beclin-1. EMBO J 2007; 26: $2527-2539$.

12. Oberstein A, Jeffrey PD, Shi Y. Crystal structure of the Bcl-XL-Beclin 1 peptide complex: Beclin 1 is a novel BH3-only protein. J Biol Chem 2007; 282: 13123-13132.

13. Pattingre S, Tassa A, Qu X, Garuti R, Liang XH, Mizushima N et al. Bcl-2 antiapoptotic proteins inhibit Beclin 1-dependent autophagy. Cell 2005; 122: 927-939.

14. Cho DH, Jo YK, Hwang JJ, Lee YM, Roh SA, Kim JC. Caspase-mediated cleavage of ATG6/Beclin-1 links apoptosis to autophagy in HeLa cells. Cancer Lett 2008; 274: 95-100.

15. Luo S, Rubinsztein DC. Apoptosis blocks Beclin 1-dependent autophagosome synthesis: an effect rescued by Bcl-xL. Cell Death Differ 2010; 17: 268-277.

16. Wirawan E, Vande Walle L, Kristof K, Cornelis S, Vanoverberghe I, Roelandt R et al. Caspase-mediated cleavage of Beclin-1 inactivates Beclin-1-induced autophagy and 
enhances apoptosis by promoting the release of proapoptotic factors from mitochondria. Cell Death Dis 2010; 1: e18.

17. Yousefi S, Perozzo R, Schmid I, Ziemiecki A, Schaffner T, Scapozza L et al. Calpain-mediated cleavage of Atg5 switches autophagy to apoptosis. Nat Cell Biol 2006; 8 : 1124-1132.

18. Hou W, Han J, Lu C, Goldstein LA, Rabinowich H. Autophagic degradation of active caspase-8: a crosstalk mechanism between autophagy and apoptosis. Autophagy 2010; 6: 891-900.

19. Fimia GM, Stoykova A, Romagnoli A, Giunta L, Di Bartolomeo S, Nardacci R et al. Ambra1 regulates autophagy and development of the nervous system. Nature 2007; 447: $1121-1125$.

20. Di Bartolomeo S, Corazzari M, Nazio F, Oliverio S, Lisi G, Antonioli M et al. The dynamic interaction of AMBRA1 with the dynein motor complex regulates mammalian autophagy. J Cell Biol 2010; 191: 155-168.

21. Strappazzon F, Vietri-Rudan M, Campello S, Nazio F, Florenzano F, Fimia GM et al. Mitochondrial BCL-2 inhibits AMBRA1-induced autophagy. EMBO J 2011; 30: 1195-1208.

22. Cecconi $F$, Levine $B$. The role of autophagy in mammalian development: cell makeover rather than cell death. Dev Cell 2008; 15: 344-357.

23. Das A, Banik NL, Ray SK. Mechanism of apoptosis with the involvement of calpain and caspase cascades in human malignant neuroblastoma SH-SY5Y cells exposed to flavonoids. Int J Cancer 2006; 119: 2575-2585.

24. Verspurten J, Gevaert K, Declercq W, Vandenabeele P. SitePredicting the cleavage of proteinase substrates. Trends Biochem Sci 2009; 34: 319-323.

25. Larsen KB, Lamark T, Overvatn A, Harneshaug I, Johansen T, Bjorkoy G. A reporter cell system to monitor autophagy based on p62/SQTM1. Autophagy 2010; 6: 784-793.
26. Rohn TT, Wirawan E, Brown RJ, Harris JR, Masliah E, Vandenabeele P. Depletion of Beclin-1 due to proteolytic cleavage by caspases in the Alzheimer's disease brain. Neurobiol Dis 2011; 43: 68-78.

27. Betin VM, Lane JD. Caspase cleavage of Atg4D stimulates GABARAP-L1 processing and triggers mitochondrial targeting and apoptosis. J Cell Sci 2009; 122: 2554-2566.

28. Cecconi F, Piacentini M, Fimia GM. The involvement of cell death and survival in neuronal tube defects: a distinct role for apoptosis and autophagy? Cell Death Differ 2008; 15: 1170-1177.

29. Klaiman G, Petzke TL, Hammond J, Leblanc AC. Targets of caspase-6 activity in human neurons and Alzheimer disease. Mol Cell Proteomics 2008; 7: 1541-1555.

30. Mookerjee S, Papanikolaou T, Guyenet SJ, Sampath V, Lin A, Vitelli C et al. Posttranslational modification of ataxin-7 at lysine 257 prevents autophagy-mediated turnover of an $\mathrm{N}$-terminal caspase-7 cleavage fragment. J Neurosci 2009; 29: 15134-15144.

31. Young JE, Gouw L, Propp S, Sopher BL, Taylor J, Lin A et al. Proteolytic cleavage of ataxin-7 by caspase-7 modulates cellular toxicity and transcriptional dysregulation. $J$ Biol Chem 2007; 282: 30150-30160

32. Ellerby LM, Andrusiak RL, Wellington CL, Hackam AS, Propp SS et al. Cleavage of atrophin-1 at caspase site aspartic acid 109 modulates cytotoxicity. J Biol Chem 1999; 274: 8730-8736.

33. Corazzari M, Lovat PE, Armstrong JL, Fimia GM, Hill DS, Birch-Machin M et al. Targeting homeostatic mechanisms of endoplasmic reticulum stress to increase susceptibility of cancer cells to fenretinide-induced apoptosis: the role of stress proteins ERdj5 and ERp57. Br J Cancer 2007; 96: 1062-1071.

34. Van de Craen M, Berx G, Van den Brande I, Fiers W, Declercq W, Vandenabeele P. Proteolytic cleavage of beta-catenin by caspases: an in vitro analysis. FEBS Lett 1999; 458: $167-170$.

\section{Supplementary Information accompanies the paper on Cell Death and Differentiation website (http://www.nature.com/cdd)}

